\title{
Behavior of innovative T-shaped multi-partition steel-concrete composite columns under concentric and eccentric compressive loadings
}

\author{
J. Chena , S.M. Zhang ${ }^{a *}$, Z.F. Huang ${ }^{a}$, X.X. Zhang ${ }^{a}$ and L.H. Guo ${ }^{\text {b,c }}$ \\ ${ }^{a}$ Shenzhen Graduate School, Harbin Institute of Technology, Shenzhen 518055, China \\ ${ }^{b}$ Key Lab of Structures Dynamic Behavior and Control of the Ministry of Education (Harbin Institute of \\ Technology), Harbin 150090, China \\ 'School of Civil Engineering, Harbin Institute of Technology, Harbin 150090, China \\ *corresponding author, e-mail address: smzhang@hit.edu.cn
}

\begin{abstract}
T-shaped multi-partition steel-concrete composite column, composed of several concretefilled rectangular steel hollow sections, is considered as an innovative composite member with the ability to accommodate neighboring wall thickness with great easiness. This paper intends to study the behavior of this innovative composite member under concentric and eccentric compressive loadings. A finite element (FE) analysis model accounting for the influences of confinement effects, geometric and material nonlinearities is developed using the program ABAQUS. The ultimate strength and load-strain responses predicted from the analysis are validated against the test results in the experiments conducted by the authors. The comparisons indicate that the FE model reasonably estimates the responses of the concentrically and eccentrically loaded T-shaped multi-partition steel-concrete composite columns. The verified model is then utilized to numerically investigate the working mechanism of the columns. The load distribution between the infilled concrete and the steel tubes and the stress distribution of the concrete during the loading process are analyzed. Moreover, parametric studies are performed to investigate the behavior of T-shaped multipartition steel-concrete composite columns under different loadings. The studied parameters include steel to concrete area ratio, concrete compressive strength, steel yield strength and load eccentricity. Combined with the experimental results, FE analysis and parametric studies, the design recommendations for T-shaped multi-partition steel-concrete composite columns under different loadings are proposed.
\end{abstract}

Keywords: T-shaped multi-partition steel-concrete composite column; finite element analysis; working mechanism; parametric studies.

\section{Introduction}

Due to the achieved advantages from the combination of the steel tube and the concrete infill, concrete-filled rectangular steel hollow section (CRSH) columns are widely used in residential buildings, which are convenient both in concrete construction and in connections with neighboring structural elements [1]. However, in most cases, CRSHs are usually protruded from the adjacent walls; this protruding leads to the reduced utilization efficiency of indoor space and furniture arrangement. In recent years, Tshaped multi-partition steel-concrete composite column, composed of several CRSHs (Fig. 1), is introduced as an innovative composite member with the convenience to align with or hide within neighboring walls.

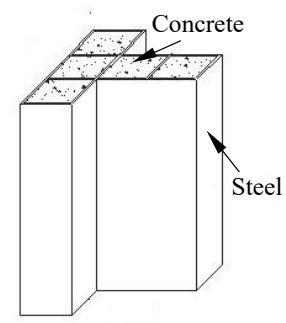

Fig. 1. Typical T-shaped multi-partition steelconcrete composite column.

During the last decade, T-shaped concrete filled steel tubular (CFST) columns without partitions (Fig. 2(a)) are also proposed to realize 
a smooth wall surface without protruding columns $[2,3]$. However, the steel tube and the concrete core tend to separate at the inner corners, thereby reducing the confinement effects, and the steel tube is also prone to buckle, especially when its depth-to-thickness ratio is large $[4,5]$. In engineering practice, the steel plate rib or pulled binding bar are usually stiffened in the T-shaped columns (Fig. 2(b)), which is the focus of the research. Experimental studies have shown that the plate rib, pulled binding bar or other stiffeners welded on the inner side of the tubes can delay the local buckling and benefit the confinement effects of the specimens [6-8]. It is noted that adding extra stiffeners would lead to additional cost from the complicated fabrication and construction. Compared with the stiffened and T-shaped CFST columns, T-shaped multi-partition steelconcrete composite column herein can be fabricated with greater facility and less costs. Despite this, the structural behavior of this innovative column has not been investigated.

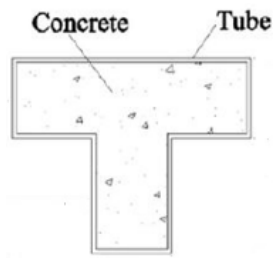

a) T-shaped CFSTs.

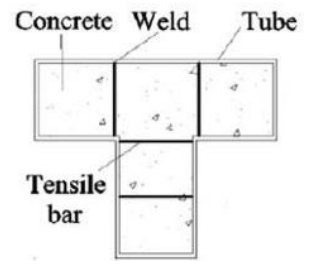

b) Stiffened CFSTs.
Fig. 2. Cross-section of T-shaped CFSTs.

This paper provides the study on the behavior of T-shaped multi-partition steel-concrete composite column under concentric and eccentric compressive loadings. A FE model was developed using the program ABAQUS and validated against test results in the experiments carried out by the authors. The verified model was then used to analyze the mechanism of the multi-partition steel tubes and infilled concrete. Parametric studies were also performed to investigate the behavior of $\mathrm{T}$-shaped multipartition steel-concrete composite columns with various geometric and material properties. Finally, design recommendations were proposed according to the numerical results.

\section{Finite element model}

\subsection{Development of FE model}

FE model is developed using ABAQUS with the aims of extending the test database and investigating the behavior of T-shaped multipartition steel-concrete composite column under concentric and eccentric compressive loadings. Eight-node solid element (C3D8R) was employed to simulate the infilled concrete while the multi-partition steel tube was modeled by four-node shell element (S4R). The meshdensity analysis on both cross-sectional and longitudinal directions were conducted to obtain an optimized mesh that can satisfy both computational accuracy and efficiency. The FE meshes for a typical member is shown in Fig. 3



Fig. 3. Mesh of a typical member.

Two rigid end plates were established with one reference point in the plane according to the applied load condition. For the stub columns under concentric loading, only one longitudinal displacement is allowed for applied load, while the other degrees of freedom were fixed for the end plates. For the slender column or the column under eccentric loading, the rotation control perpendicular to eccentric direction is also allowed in the cross-section. To simulate the surface-to-surface contact between the infilled concrete and the outer steel tubes, the 'hard' contact behavior and Coulomb friction model with coefficient of 0.3 is employed in the normal and tangential direction, respectively. In addition, the rigid end plates were tied to the edge of the multi-partition steel tubes.

The concrete damage plasticity model introduced in ABAQUS, which is capable of analyzing concrete under multiaxial state, models the infilled concrete. The key material parameters determined in this model include the compressive meridian $\left(K_{\mathrm{c}}\right)$, dilation angle $(\psi)$, flow potential eccentricity (e), ratio of the compressive strength under biaxial loading to uniaxial compressive strength $\left(f_{\mathrm{b} 0} / f_{\mathrm{c}}\right)$, and viscosity parameter $(\mu)$. These parameters can be defined according to the suggestions by Tao et al. [9], which takes the characteristics of passively confined concrete into account. Different stressstrain models with the ability to determine the strain hardening/softening function directly have been proposed by researchers for FE modelling 
of confined concrete in steel tubes. In this study, the model suggested by Tao et al. is adopted, since the model is more versatile and accurate in modelling axially loaded CFST stub columns [9].

For steel material, the Von-Mises yield criterion with associated plastic flow and isotropic strain hardening were employed in the plastic model. The elastic-plastic stress-strain model with linear hardening for steel is adopted herein, where the strain hardening modulus was taken as $0.01 E_{\mathrm{s}}$. The elastic modulus $E_{\mathrm{s}}$ and Poisson's ratio of steel is taken as $2.06 \times 10^{5} \mathrm{MPa}$ and 0.283 , respectively in the parametric studies later in this study.

\subsection{Model validation}

The experimental data collected from the study by the authors $[10,11]$ was employed to validate the proposed FE model herein. The tests include 2 concentrically loaded and 2 eccentrically loaded T-shaped multi-partition steel-concrete composite columns. From these columns, the length of the side in each steel tube is $100 \mathrm{~mm}$, the side length is $300 \mathrm{~mm}$ in crosssection with 3 steel tubes in both flange and web directions, the lengths of the column specimens are $400 \mathrm{~mm}$ and $1200 \mathrm{~mm}$, respectively, and the eccentricity is $50 \mathrm{~mm}$ for the eccentrically-loaded specimens. An example of the test specimen identification system is as follows: C-400, where the letter $\mathrm{C}$ denotes concentric loading while $\mathrm{E}$ is eccentric loading, and the number 400 represents the length of the column. The elastic modulus of the steel was measured as $2.06 \times 10^{5} \mathrm{MPa}$, and the yield and ultimate strength is $299.7 \mathrm{MPa}$ and 415.6 $\mathrm{MPa}$, respectively. The measured elastic modulus and cubic strength of the concrete is $3.20 \times 10^{4} \mathrm{MPa}$ and $51.6 \mathrm{MPa}$, separately.

The load-strain curve for the concentrically loaded specimens and the load-midspan deflection behavior for the eccentrically loaded specimens predicted from the developed FE model and the corresponding test results are compared in Fig. 4 and Fig. 5, respectively. It can be noted that the FE model in this study generally predicts well for the overall trend of the load-strain and load-midspan deflection curves of the test columns. The initial stiffness form the FE models also reasonably agree with the experimental ones. A comparison between the peak loads predicted by the FE models and the experimental results is also evaluated. The average of the predicted to measured values is 1.008 for the considered columns and the corresponding coefficient of variation is only 0.019 . The results indicate that the developed FE model accurately predicts the peak load of the concentrically loaded and eccentrically loaded test columns. Based on the comparisons, it is suggested that the proposed FE model can be applied to predict the concentric and eccentric compressive behavior of T-shaped multipartition steel-concrete composite columns.

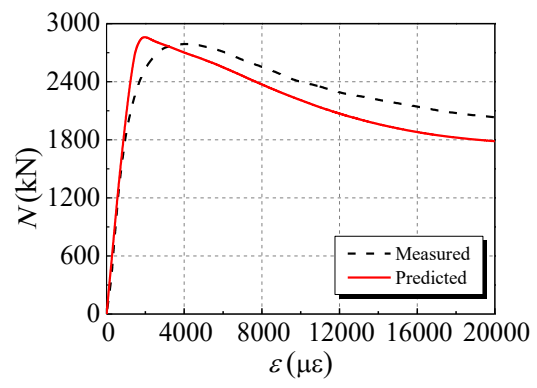

a) A-400.



b) A-1200.

Fig. 4. Compassion of predicted load versus strain curves and with experimental ones by the authors [10].

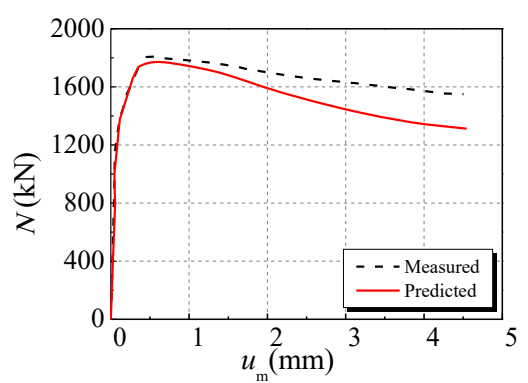

a) E-400

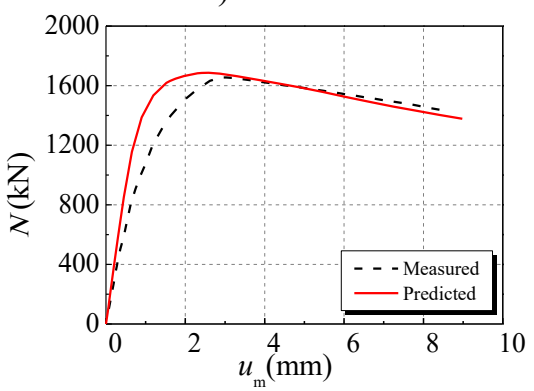

b) E-1200.

Fig. 5. Compassion of predicted load versus mid-span deflection curves and with experimental ones by the authors [11]. 


\section{Working mechanism analysis}

A typical cross-sectional numerical sample for the T-shaped multi-partition steel-concrete composite column was established using the verified FE model in this study. The dimensions and material properties of the cross-sectional numerical model are as follows: the lengths of the flange and the web are both equal to $300 \mathrm{~mm}$, the side length and the wall thickness of the steel tube is $100 \mathrm{~mm}$ and $2 \mathrm{~mm}$, respectively. The concrete compressive strength is $32.4 \mathrm{MPa}$ and the steel yield strength is $235 \mathrm{MPa}$. The eccentricity is $100 \mathrm{~mm}$ from the centroid for the eccentrically loaded cross-section. The working mechanism analysis is conducted in terms of the load distribution between the infilled concrete and the steel tubes during the loading process, and the stress distribution of the concrete when the cross-section reaches the bearing capacity.

\subsection{Load distribution}

The load-vertical strain relationship for the concentrically loaded and eccentrically loaded cross-sections of the columns are shown in Fig. 6. The load distribution between the infilled concrete and the steel partition during the loading process is also depicted in the figure.

As can be seen in Fig. 6(a), the load-vertical strain curve can be generally divided into three stages consisting of elastic (OA), elasto-plastic $(\mathrm{AB})$ and plastic softening $(\mathrm{BC})$ stages. In the elastic stage, the outer steel tube and infilled concrete bear the load independently, and there is almost no interaction developed between the steel tube and the infilled concrete in the initial stage. This is because the Poisson's ratio of the concrete is lower that of the steel, which leads to smaller lateral deformation of the concrete than that of the steel. With the increasing vertical strain, due to the cracks developed in the concrete, the lateral deformation rate of the concrete starts to exceed that of the steel tube, and the confinement stress therefore occurs and develops. After the stress of the steel reaches the maximum value, the vertical stress in the steel starts to decrease, due to the increased circumferential stress developed from the lateral expansion of the concrete. Meanwhile, with a growing of the confinement effects, the vertical strength of the concrete core continues to increase gradually. This indicates that there is a load distribution between the steel tube and infilled concrete as shown in Fig. 6(a). In this stage, the increase of load sustained by the concrete is larger than the decrease of the load carried by the steel, thereby leading to an increase in the load of the cross-section. At the point $\mathrm{B}$, the cross-section and the infilled concrete reach their peak strengths. Afterwards, the strength of concrete decreases, resulting in a reduction in the load of the cross-section.

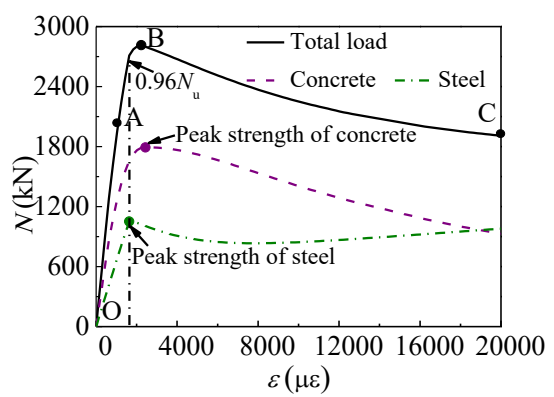

a) Concentrically-loaded.

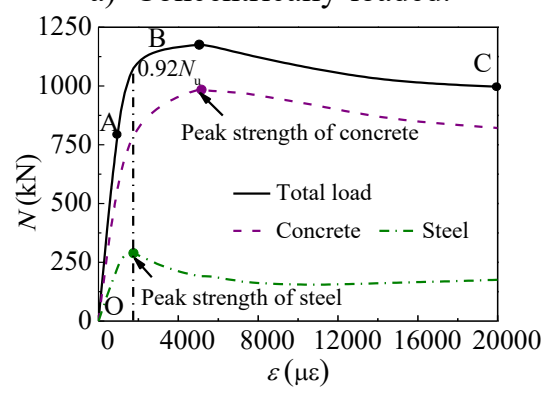

b) Eccentrically-loaded.

Fig. 6. Load distribution during loading process.

The analytical results in Fig. 6(b) also shows that for the eccentrically loaded cross-section, the bearing capacity of the steel tubes has reached the maximum value before the crosssection attains the peak load, while the stress of the concrete continues to increase. However, the steel achieves the maximum value at a lower load ratio of 0.92 as compared to that of 0.96 shown as in Fig. 6(a).

\subsection{Stress distribution of concrete}

Fig. 7 provides the vertical stress distribution for the infilled concrete when the cross-section of the columns reaches the peak load.

The stress distribution of the concrete in Fig. 7(a) shows that the concrete around the corner of the steel tubes have the highest stress in the cross-section due to the greatest confinement effects in these areas. According to these, the stress of the concrete around the two sides of the inner steel plates is higher than that around the center of the tubes. It is worth noticing that the stress in these areas are higher than that of unconfined concrete due to the confinement effects, while the stress of the concrete around the center 
of free edge of the tube is almost equal to uniaxial compressive strength of concrete. In addition, the steel tubes can also be classified into three types according to the stress distribution of the concrete. For example, the stress distributions of the tubes 1,4 and 5 with three free edges in the figure perform similar behavior, while the tube 2 and 3 exhibits the other two types of stress distribution for concrete, respectively. Thus, the cross-sectional resistance is suggested to be calculated based on the confinement distribution and the types of the stress distributions.

The stress distribution of the concrete for eccentrically loaded cross-section depicted in Fig. 7(b) shows that there are stresses distributed in tensile in the tubes 3, 4 and 5 as red areas. It can also be noted that the confinement effects provided by the steel tubes in the compressive zones are greater than those in the tensile zones.

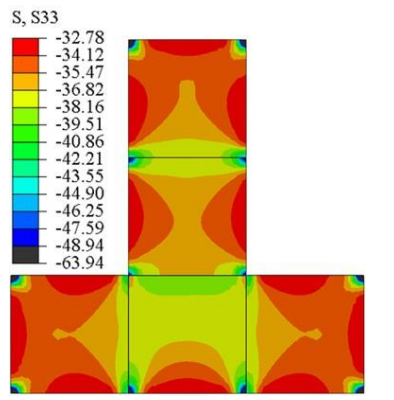

a)

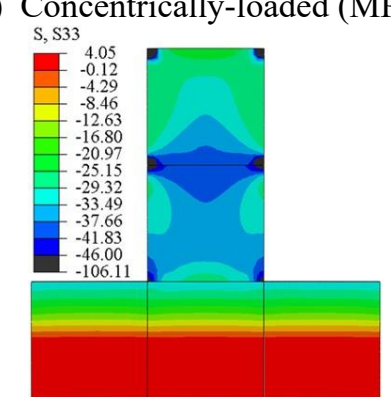

b) Eccentrically-loaded (MPa).

Fig. 7. Stress distribution of concrete.

\section{Parametric study}

Parametric studies based on the FE model proposed in this study were conducted to examine the cross-sectional behavior of $\mathrm{T}$ shaped multi-partition steel-concrete composite columns under concentric and eccentric compressions. These responses consist of the load-strain, load-moment relationships and their corresponding normalized curves.

The cross-sectional dimensions of all the numerical models in this analysis are identical with the typical numerical sample in section 3. Various geometrical and material parameters were considered. In terms of the geometry, the wall thicknesses of steel tubes with 2, 2.5, 3.5 and $4 \mathrm{~mm}$ resulting in the steel to concrete area ratios of $0.064,0.080,0.096$ and 0.128 were evaluated. Regarding variations in material properties, the analysis covers four different concrete compressive strength grades with characteristic cubic strength of $30,40,50$ and $60 \mathrm{MPa}$, and three steel characteristic yield strengths of 235, 345 and $390 \mathrm{MPa}$.

\subsection{Influence of steel to concrete area ratio}

Previous studies on CFST columns indicate that the steel to concrete area ratio plays a significant role in the confinement effects. The influence of the steel to concrete area ratio was investigated by changing the wall thickness of the steel tubes. The concrete compressive cubic strength is $50 \mathrm{MPa}$, and the steel yield strength is $235 \mathrm{MPa}$.

The influence of various steel to area ratios on the load-strain behavior of concentrically loaded columns is shown in 0 . In can be noted that both the initial stiffness and the load-bearing capacity increase when the steel to area ratio increases as shown in 0 (a). This is because the contributions of the steel tube to the stiffness and strength are improved when steel to concrete area ratio increases. In addition, the ductility also has been improved observed from the normalized load-strain curves in $0(\mathrm{~b})$, due to the greater confinement effects acting on concrete core for the member with higher steel to concrete area ratio.

In terms of the eccentrically loaded behavior, the load-moment interaction curves for the columns under various eccentricities in $0(\mathrm{c})$ show that both the axial load capacity and the pure bending moment capacity of the column increase with the increasing steel to concrete area ratio. It is worth noting that the pure bending moment capacity is more sensitive to the steel to concrete area ratio than the axial load capacity. The reason is that the increase in the value of pure bending moment is $56.5 \%$ as compared to $32.1 \%$ for the axial load capacity when the steel to concrete area ratio of the column increases from 0.064 to 0.128 . This reveals that the contribution of the steel to concreate area ratio in the cross-sectional pure bending moment is higher to that in the axial load capacity. The normalized load-moment interaction curves in 
0 (d) shows that, for the cross section with steel to concrete area ratio of 0.064 , the moment capacity increases slightly when the ratio of load capacity to cross-sectional capacity $N / N_{\mathrm{u}}$ less than of 0.1. Afterwards, the moment capacity decreases significantly with the increasing load capacity. The members with larger steel to concrete area ratios achieve their largest moment capacities under pure bending. In addition, there is a horizontal shift in the normalized interaction curve when the ratio $N / N_{\mathrm{u}}$ is less than 0.4 , while the curves almost coincide with each other for the columns under larger load ratios, regardless of the steel to concrete area ratio.

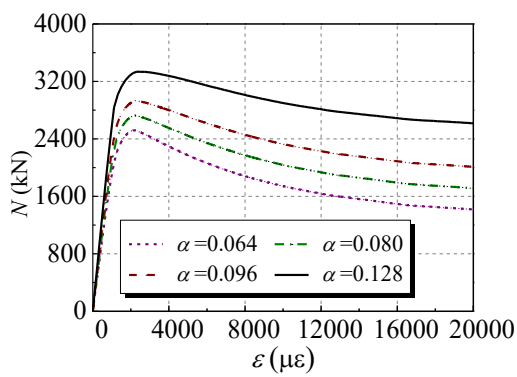

a) Load-strain relationship.



b) Normalized load-strain relationship.

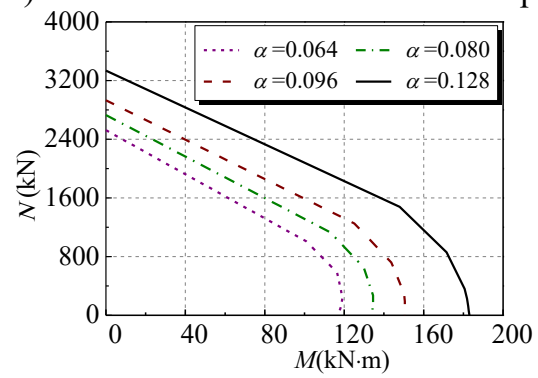

c) Load-moment interaction relationship.

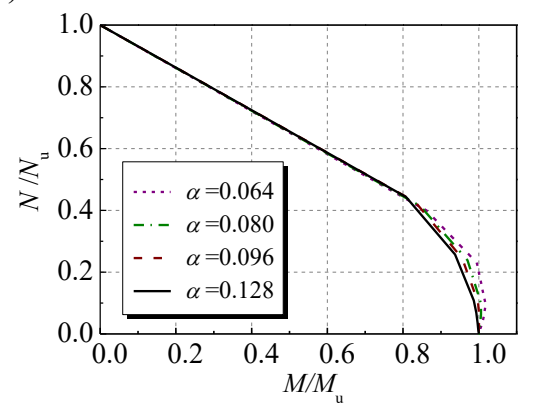

d) Normalized load-moment interaction curve.

Fig. 8. Influence of steel to concrete ratio.

\subsection{Influence of concrete compressive strength}

The concentrically loaded and eccentrically loaded responses of the columns were analyzed with concrete cubic strengths varying between $30 \mathrm{MPa}$ and $60 \mathrm{MPa}$. The steel to concrete area ratio is 0.096 and the steel yield strength is $235 \mathrm{MPa}$ in this analysis.

Fig. 9(a) depicts the load-strain behavior for columns with various concrete compressive strengths. As expected, both the initial stiffness and the peak load increase when the concrete compressive strength increases. It can be noted that the strain ductility decreases with increasing concrete compressive strength as depicted in Fig. 9(b). This is attributed to the brittle performance of the high strength concrete.

As illustrated in Fig. 9(c), the column with higher concrete compressive strength exhibits larger axial load and pure bending moment capacities. It can also be observed that the influence of concrete compressive strength on the axial load capacity is more obvious than that on the pure bending moment, since an increase of $42.1 \%$ is noted in the axial load capacity as compared to $23.7 \%$ in the pure bending moment when the concrete compressive strength varies from $30 \mathrm{MPa}$ to $60 \mathrm{MPa}$. The results in Fig. 9(d) indicate that the concrete compressive strength has no significant effects on the envelop curve of the normalized interaction relationship.

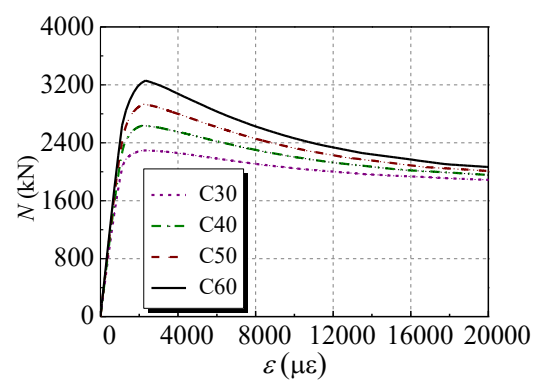

a) Load-strain relationship.

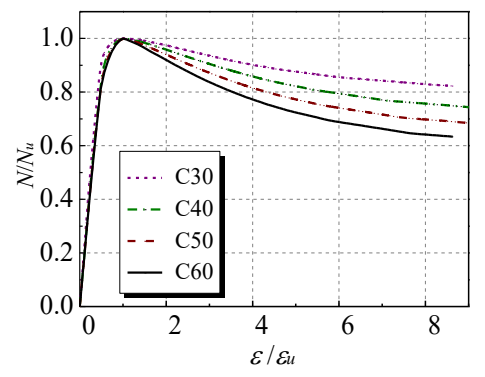

b) Normalized load-strain relationship. 


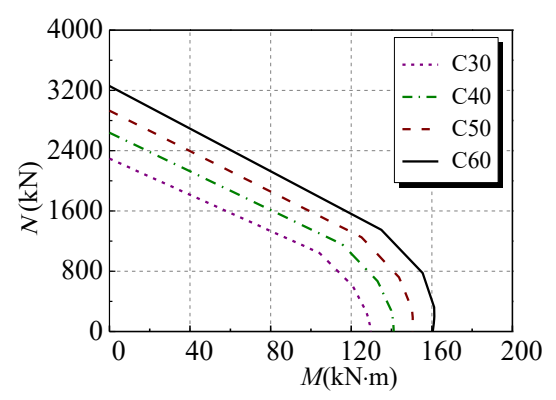

c) Load-moment interaction relationship.

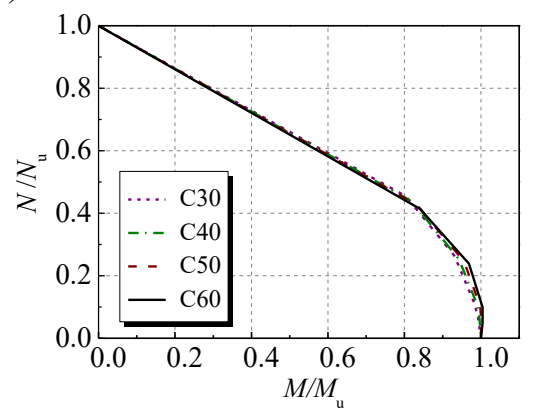

d) Normalized load-moment interaction curve.

Fig. 9. Influence of concrete strength.

\subsection{Influence of steel yield strength}

The influence of the steel yield strength on the behavior of columns under concentric and eccentric loads are also examined in this study. The steel to concrete area ratio is 0.096 and the concrete compressive strength is $50 \mathrm{MPa}$ in this analysis.

The load-strain responses for the columns with different steel yield strength is depicted in Fig. 10(a). As expected, the initial stiffness is not affected by the steel strength, and increasing the strength significantly increases the peak crosssectional resistance of the columns. In addition, the ductility has also been improved because the increase in the steel yield strength benefits the confinement effects of the steel to the infilled concrete, thereby improving the composite behavior of the member.

Compared to the results in $0(\mathrm{c})$, the loadmoment interaction curves in Fig. 10(c) also indicate that the contribution of the steel yield strength in the cross-sectional pure bending moment is higher to that in the axial load capacity. For example, the pure bending capacity and the axial load capacity increases by $39.1 \%$ and $26.7 \%$, respectively when increasing the steel yield strength from $235 \mathrm{MPa}$ to $390 \mathrm{MPa}$. The steel yield strength also has no significant effects on the envelop curve of the normalized load-moment interaction relationships as observed in Fig. 10(d).

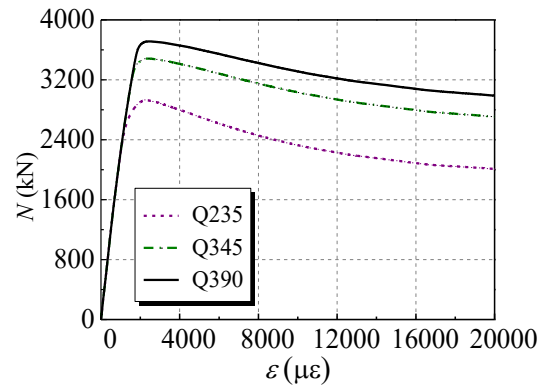

a) Load-strain relationship.

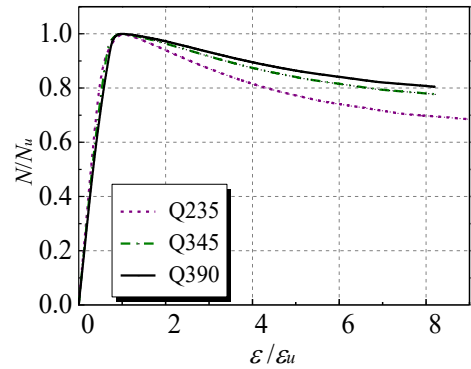

b) Normalized load-strain relationship.

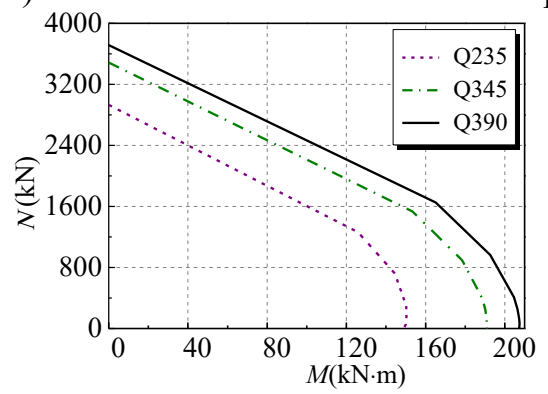

c) Load-moment interaction relationship.

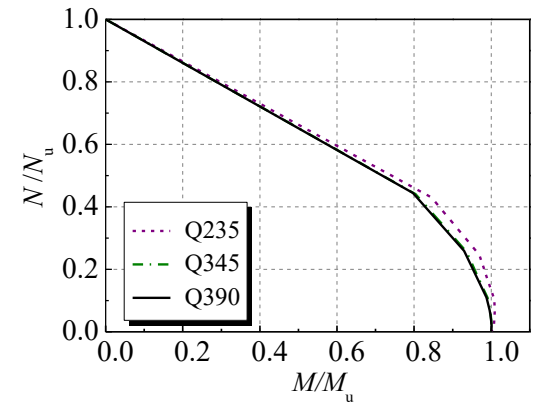

d) Normalized load-moment interaction curve.

Fig. 10. Influence of steel yield strength

\section{Conclusion}

A FE model was developed and validated for analyzing the behavior of T-shaped multipartition steel-concrete composite column under concentric and eccentric compression. The FE model is then utilized to investigate the working mechanism of the columns. Parametric studies are also performed to investigate the key factors on the behavior of the columns. Based on the study, the following conclusions can be obtained:

1) The developed FE model can reasonably predict the peak load and load-strain 
responses of the $\mathrm{T}$-shaped multipartition steel-concrete composite column under concentric and eccentric compression.

2) For the concentrically loaded member, the confinement effects mainly act on the concrete around the corner and the center of the tubes the two sides of the inner steel plates. The stress distribution of the concrete can be classified into three types. Further calculation of the cross-sectional resistance is suggested to be employed based on the confinement distribution and the types of the stress distributions.

3) For the eccentrically loaded member, the confinement effects provided by the steel tubes in the compressive zones are greater than those in the tensile zones.

4) Parametric studies indicate that the influences of the steel to concrete area, concrete compressive strength and steel yield strength on the concentric-loaded T-shaped multi-partition steel-concrete composite members are similar to those on the axial responses of CFSTs. The concrete compressive strength and the steel yield strength have no significant effects on the envelop curve of the normalized load-moment interaction relationship for the members.

\section{Acknowledgments}

The research work reported in this paper were supported by National Key Research and Development Program (2016YFC0701201), and National Natural Science Foundation of China (Grant No. 51578187); their financial supports are highly appreciated.

\section{References}

[1] Han LH, Li W, Bjorhovde R. Developments and advanced applications of concrete-filled steel tubular (CFST) structures: members. Journal of Constructional Research 2014; 100: 211-228.

[2] $\mathrm{Lu} \mathrm{XL}, \mathrm{Li}$ XP, Wang D. Modelling and experimental verification on concrete-filled steel tubular columns with $\mathrm{L}$ or $\mathrm{T}$ section. Frontiers of Architecture \& Civil Engineering in China 2007; 1: 163-169.

[3] Yang YL, Yang H, Zhang SM. Compressive behavior of T-shaped concrete filled steel tubular columns. International Journal of Steel Structures 2010; 10: 419-430.

[4] Zhang S M, Guo L H, Ye Z L, Wang Y. Behavior of Steel Tube and Confined High Strength Concrete for Concrete-Filled RHS Tubes. Advances in Structural Engineering 2005; 8: 101-116.

[5] Guo L H, Zhang S M, Kim W J, Ranzi G. Behavior of square hollow steel tubes and steel tubes filled with concrete. Thin-Walled Structures 2007; 45(12): 961-973.

[6] Cai J, He Z Q. Axial load behavior of square CFT stub column with binding bars. Journal of Constructional Steel Research 2006; 62: 472483.

[7] Zhou T, Chen ZH, Liu HB. Seismic behavior of special shaped column composed of concrete filled steel tubes. Journal of Constructional Steel Research 2012; 75: 131-141.

[8] Yang YL, Wang YY, Fu F, Liu JC. Static behavior of T-shaped concrete-filled steel tubular columns subjected to concentric and eccentric compressive loads. Thin-Walled Structures 2015; 95: 374-388.

[9] Tao Z, Wang ZB, Yu Q. Finite element modelling of concrete-filled steel stub columns under axial compression. Journal of Constructional Steel Research 2013; 89: 121131.

[10]Zhang XX. Mechanical behavior of T-shaped multi-partition steel-concrete composite shear walls with limited width under axial compression. MS thesis. Shenzhen: Harbin institute of technology; 2017.

[11]Huang ZF. Mechanical behavior of T-shaped multi-partition steel-concrete composite shear walls with limited width under eccentric compression. MS thesis. Shenzhen: Harbin institute of technology; 2017. 